\title{
Improved Aboriginal child health data collection urged
}

Published at www.cmaj.ca on Nov. 30

I nitiatives to improve the health of indigenous children in Canada, Australia and New Zealand are stymied by gaps and deficiencies in health data, the National Aboriginal Health Organization conference was told in November.

Good data are essential for introducing and evaluating policies aimed at improving health status, Dr. Jane Freemantle of the University of Melbourne's school of population health in Melbourne, Australia, told participants at the Ottawa, Ontario, conference.

"With good statistics, we could, for example, compare infant mortality figures across the countries and look to see what are best practices" to improve outcomes, she said after her talk.

However, while the overall poorer health status of indigenous children compared to their nonindigenous counterparts is documented, deficiencies and differences in data make cross-country comparisons difficult, she said.

The three Aboriginal groups share histories of white colonization, the loss of traditional lifestyles and exclusionary social policies that have led to health consequences, such as poor nutrition and significantly lower life expectancies, she said.

Some striking disparities in child health common to the three countries include indigenous infant mortality rates that are 1.7 to 4 times higher than nonindigenous infants, and higher rates of suicide, respiratory tract illnesses, dental problems and exposure to environmental contaminants, according to the 2009 Indigenous Children's Health Report; Health Assessment in Action. Freemantle was an author of the study, published by the Centre for Research on Inner City Health at St. Michael's Hospital in Toronto.

Faulty or culturally biased data collection can also seriously affect how health issues are measured and

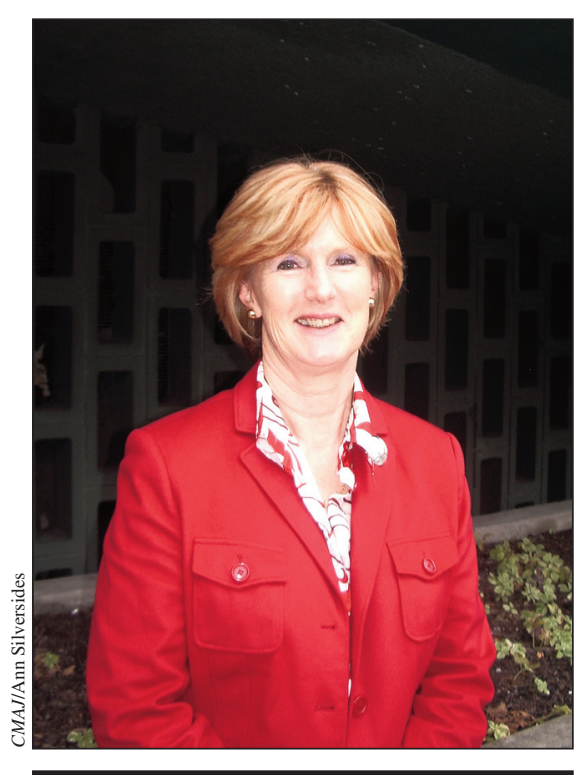

Good data are essential for introducing and evaluating policies aimed at improving Aboriginal child health, says Dr. Jane Freemantle of the University of Melbourne's school of population health in Melbourne, Australia.

dealt with within each country, she noted.

Unlike Australia and New Zealand, Canada doesn't track information about hospitalization and child mortality rates for Aboriginal people and this leads to an "inability to identify and respond to major potentially reversible health status inequities, such as accidents and infectious diseases of the respiratory and gastrointestinal systems," Freemantle told the conference, which took place Nov. 24-26.

In Australia, data describing indigenous people are not available from all states, and Aborigines were not included in the national census before 1967, she added.

And until 1995 in New Zealand, only people with at least half Maori blood were identified as Maori in national data relating to births and deaths, she said. This definition was inconsistent with the national census which had, since 1986, accepted the self-identification of Maori people.
The impact of public health measures on Aboriginal people can also be obscured if their data are not separately reviewed, she said. For example, an Australian education campaign aimed at reducing the incidence of neural tube defects appeared to have positive results, with overall rates declining over the 11-year period, she said. But when statistics for Aboriginal births were reviewed, it became apparent those rates had remained unchanged.

The failure of an educational campaign promoting the role of folic acid within the Australian Aboriginal community prompted researchers to successfully push for the mandatory fortification of flour with folic acid, which was introduced this year. (In Canada, flour has been fortified with folic acid since 1998. A Canadian study published in 2007 noted that between 2000 and 2002 , the rate of neural tube defects in newborns dropped $46 \%$ to 0.86 .)

Similarly, when sudden infant death syndrome for Australian Aboriginal people was isolated from the overall population, it showed the death rate was almost eight times higher than for non-Aboriginal children, Freemantle told the conference.

That led to an education prevention campaign targeting the Aboriginal population, many of whom had understood the syndrome to be a European disease associated only with the use of cribs, because it had been commonly referred to as "crib death," she later said in an interview.

In Canada, a key problem for public health assessment is the fact that individuals cannot self-identify as First Nations, Inuit or Métis in most health data systems, including vital registries, primary care and hospital records and surveillance systems, according to the Indigenous Children's Health Report, which was funded by Health Canada. — Ann Silversides, CMAJ

DOI:10.1503/cmaj.109-3119 